\title{
LOS DIVOS DE ÓPERA EN EL CINE: LAS RETRANSMISIONES LIVE IN HDTRANSFORMAN EL STAR SYSTEM LÍRICO
}

\author{
Operatic divos in the movies: \\ Live in HD broadcasts transform the star system
}

ISABEL Villanueva Benito ${ }^{\mathrm{a}}$ University of California

IvÁN LACASA MAS Universitat Internacional de Catalunya

JAUME RADigALES BABI ${ }^{\mathrm{c}}$ Universitat Ramon Llull

DOI : http://dx.doi.org/10.15366/secuencias2018.47.002

\begin{abstract}
RESUMEN
Durante más de cien años, la industria de la ópera ha utilizado la atracción que los divos han provocado en el cine y los medios de comunicación para ampliar sus audiencias. Tras la digitalización, el mercado global de las retransmisiones de ópera en los cines ha replanteado la función que para este género musical tienen tanto los medios digitales como su star system en el proceso de atracción de audiencias masivas. En este artículo analizamos cuál ha sido la imagen global de los cantantes de ópera ofrecida por el cine y la televisión durante el siglo xx para identificar los principales cambios que las retransmisiones de ópera en los cines han ocasionado en el star system operístico durante el siglo xxi. Las proyecciones vía streaming parecen haber configurado una imagen del cantante mainstream más global, humana y comprometida, capaz de actualizar la idea que de este arte tiene la sociedad.
\end{abstract}

Palabras clave: Opera, divos, cine, medios audiovisuales, audiencias, imagen

\section{ABSTRACT}

For a hundred years, the opera industry has used the attraction that its singers have provoked in film and media to expand the audiences. After the digitization age, the global market for opera retransmissions in theaters has rethought the role of digital media and its star system in the process of attracting new audiences. In this article we analyze what has been the global image of the opera singers offered by the cinema and television during the $\mathrm{xx}$ century, to identify the main changes that the opera retransmissions in the theaters have promoted in the operatic system in xxi century. The streaming projections seem to have configured an image of the mainstream singer, more global, human and committed, able to update the social conception of this art.

Keywords: Opera, divos, film, Audiovisual Media, audiences, image

[a] Isabel Villanueva Benito es Doctora en Comunicación; Licenciada en Comunicación Audiovisual y Publicidad y Relaciones Públicas y Graduada superior en Música (especialidades de canto y composición). Trabaja como Profesora Contratada Doctor de la Universitat Internacional de Catalunya (UIC) y Visiting Researcher en la University of California, Los Ángeles. Ha sido Posdoctoral Scholar en la convocatoria de 2017 del programa Fulbright de intercambio académico entre España y Estados Unidos y Vicedecana de la Facultad de Ciencias de la Comunicación de la UIC durante los años 2011-2016. E-mail: ivillanueva@uic.es

[b] Iván Lacasa Mas es Profesor Titular de Teoría de la Comunicación en la Universitat Internacional de Catalunya. Es Doctor por la Universitat Autònoma de Barcelona (Departament de Periodisme i Ciències de la Comunicació), Máster en estadística aplicada por la Universidad Rey Juan Carlos y Licenciado en Filosofía por la Universitat de Barcelona. Trabaja como Visiting Scholar en la University of Texas at Austin, donde forma parte del «Center for Media Engagement» y del «Digital Media Research Project». También es Investigador Principal del grupo «Comunicació, Mitjans i Societat» (AGAUR) y miembro del proyecto de investigación «Usos y preferencias informativas en el nuevo mapa de medios en España» (Ministerio de Economía y Competitividad). E-mail: lacasa@uic.es

[c] Jaume Radigales es Doctor en Historia del Arte por la Universitat de Barcelona y Profesor Contratado Doctor en la Facultat de Comunicació i Relacions Internacionals Blanquerna de la Universitat Ramon Llull, donde es profesor de Estética y de Narrativa de Géneros Audiovisuales. Es asimismo profesor del máster «La música como arte interdisciplinar» en la Universitat de Barcelona. Ha publicado distintos libros sobre las relaciones entre la música y el audiovisual, especialmente centrados en la ópera y el cine, y ha sido Investigador Principal de dos I+D sobre las relaciones entre la música y el cine en España. Colabora asiduamente en la emisora radiofónica Catalunya Música, donde realiza y presenta el programa «Una tarda a l’òpera». Es corresponsal en Barcelona de la revista Ritmo (Madrid) y ejerce la crítica musical en La Vanguardia y en Ópera actual. E-mail: JaumeRB@blanquerna.url.edu 


\section{Introducción}

Lejos de olvidar las vinculaciones históricas que la ópera había establecido con los medios de comunicación durante el siglo $\mathrm{xx}^{1}$, en el siglo xxi las retransmisiones de ópera en los cines han contribuido a actualizar y engrandecer la imagen de este arte entre las audiencias globales ${ }^{2}$. Gracias a estas retransmisiones, conocidas como Live in HD, Digital Broadcast Cinema (DBC) u Opera in Theatres, la ópera ha sido capaz de explorar nuevos mercados comerciales ${ }^{3}$. Hoy, el Live in HD constituye un negocio mundial consolidado y se ha erigido como el espectáculo escénico pionero en sacar, vía streaming, la producción en directo fuera de los teatros mediante su grabación, retransmisión y comercialización a través de las pantallas, con sistemas que potencian la transmisión en directo, como el webcast y el cinecast ${ }^{4}$. Precisamente, estos contenidos audiovisuales, considerados alternativos al discurso cinematográfico, son los que, en los últimos diez años, han logrado que en Europa el número de espectadores en las salas de cine haya aumentado ${ }^{5}$. En España, Cinesa, Yelmo y Kinepolis, principales ofertantes de estos nuevos servicios, señalan que las temáticas preferidas por estas nuevas audiencias, no especialmente cinéfilas, son la ópera, el fútbol y los conciertos musicales, los cuales triunfan sobre el ballet, el circo en vivo, los musicales de Broadway u otros eventos deportivos como el baloncesto y el rugby, que tienen mayor aceptación en otros países de Europa ${ }^{6}$.

Desde el punto de vista de las audiencias, la posibilidad de apreciar el espectáculo en los cines vía streaming, sin la necesidad de acudir a los teatros, no solo ha contribuido a la descentralización de un arte considerado elitista por tradición, sino que ha revalorizado y expandido la ópera como mundo de referencia al que asociar deseos y conductas de sus públicos. Conscientes del potencial valor que la digitalización y la audiovisualización de las obras aporta a la industria operística, los principales teatros se han lanzado a la difusión
[1] De acuerdo con Schroeder (David Schroeder, Cinema's Illusions, Opera's Allure. [New York, The Continuum International Publishing Group, 2002] p.1) en los inicios del cine, realizadores como Cecile B. DeMille o Charles Chaplin utilizaron argumentos operísticos en sus películas para obtener el reclamo de nuevos públicos. Posteriormente, con la llegada del cine sonoro, se recurrió a la ópera como excusa ambiental en la que situar la acción dramática de las películas. Autores como Marcia Citron (Opera on Screen [London, Yale University Press, 2000], pp. 4-19) reconocen también la proliferación de biopics sobre los divos o la ópera grabada como documento de archivo. Pero ha sido la denominada ópera filmada el producto más estable, aceptado y prolífico que ha existido desde los años treinta del pasado siglo hasta nuestros días. Son este tipo de películas las que lograron obtener cierto reconocimiento audiovisual, gracias a la aportación cinematográfica de realizadores como Ingmar Bergman, Joseph Losey o Hans Jürgen Syberberg, entre otros.

[2] Iván Lacasa, Isabel Villanueva, «La digitalización audiovisual de la ópera. Nuevos medios, nuevos usos, nuevos públicos» (Telos, vol. 88, 2011), pp. 65-74.

[3] Isabel Villanueva-Benito, Mediatización audiovisual de la ópera como proceso de apertura a nuevos públicos; el caso de la obra Don Giovanni de W. A. Mozart, (tesis doctoral, Barcelona, Universitat Internacional de Catalunya, 2014), pp. 621.

[4] Según Sergi Sánchez («La ópera en pantalla grande. Entrevista a José Batlle» [Opera Actual, vol. 116, 2008], pp. 36-37.), en España, este nuevo tipo de retransmisión en los cines ha ofrecido significativos episodios desde su aparición en 2006. Cabe citar como ejemplos el éxito de asistencia que logró la retransmisión 3D de un concierto de Alejandro Sanz en las salas Kinépolis de Madrid, en octubre de 2010; la ya tradicional retransmisión del «clásico» futbolístico Barcelona vs. Real Madrid, que comenzara con la experiencia en pantalla gigante ofrecida en el Cinestadium, inventado por Yelmo y Mediapro el pasado 2010; o la retransmisión en 3D del inicio de la FIFA World Cup, en la primavera de ese mismo año. De hecho, España es el país en el que se iniciaron las primeras pruebas piloto de retransmisiones de contenidos específicos de ópera, en el año 2004, de la mano de Cinesa y el Gran Teatre del Liceu de Barcelona.

[5] De acuerdo con José María Álvarez Monzoncillo, Cine: riesgos y oportunidades se equilibran ante el cambio digital. Hacia un nuevo sistema mundial de comunicación. Las industrias culturales en la era digital (Madrid, Gedisa, 2003), y Fernando Huertas, «El futuro digital del cine» (Telos, Vol. 51, 2002), pp. 78-89, entre los principales factores del gran cambio de paradigma en la exhibición cinematográfica se cuentan las modificaciones de los hábitos de ocio de los consumidores, la consolidación del uso de tecnología digital, la alteración de las ventanas de exhibición o la oferta de nuevos tipos de contenidos audiovisuales. De todos ellos, es precisamente este último factor el que plantea mayores oportunidades de negocio, al atraer a nuevos consumidores.

[6] José María Ávarez Monzoncillo, Cine: riesgos y oportunidades se equilibran ante el cambio digital. Hacia un nuevo sistema mundial de comunicación. Las industrias culturales en la era digital, pp. 85-110. Jessica Izquierdo, «El impacto de la tecnología en la exhibición cinematográfica: el lento camino a la sala digital» (Revista Latina de Comunicación Social, vol. 12, no 64, 2009). 
[7] Hoy, numerosos gerentes, tales como Plácido Domingo o Gérard Mortier, han manifestado su voluntad de que cineastas como Woody Allen, George Lucas o Pedro Almodóvar asuman también la dirección de títulos operísticos. Jaume Radigales, «Playback problems when Filming Opera for the Screen: Two Case Studies», en Opera and Video. Technology and Spectatorship (Bern, Peter Lang, 2012), pp. 115-127.

[8] Isabel Villanueva-Benito, Mediatización audiovisual de la ópera como proceso de apertura a nuevos públicos; el caso de la obra Don Giovanni de W. A. Mozart, pp. 621.

[9] Youssef Ishaghpour, Opéra et théâtre dans le cinéma d'aujourd'hui, (París, La Différence, 1995).

[10] Véase Marcia Citron, Opera on Screen. Walter Benjamin, «La obra de arte en la época de su reproductibilidad técnica», en Discursos interrumpidos I, (Buenos Aires, Taurus, 1989).

[11] John Roselli, «La ópera como acontecimiento social», en Historia ilustrada de la ópera (Barcelona, Paidós Ibérica, 1998), pp. 450-482.

[12] Mia Bongiovanni, «Entrevista realizada por una de las autoras a la responsable de las retransmisiones en HD para los cines del Metropolitan Opera House de Nueva York», (Nueva York, 6 de octubre de 2017). multiplataforma de sus programaciones y han reforzado esta iniciativa con la creación de una estructura mediática y comercial capaz de alimentar su presencia continuada en los espacios de consumo audiovisual.

En concreto, los organismos introducen la marca operística mediante la utilización de la imagen de los divos en espacios públicos propios de los medios de comunicación, como los cines o los auditorios. La ópera recurre así al reclamo comercial de sus estrellas para explorar nuevos mercados, no necesariamente musicales. El liderazgo de campañas mediáticas por parte de cantantes y directores musicales se ha extendido de forma global y es reforzado por un contexto en el que parece estar de moda que los cineastas y los escenógrafos exploren vías creativas del cine y de la lírica intercambiando sus roles. De este modo, los teatros y los festivales han acogido puestas en escena de óperas de Wagner, Mozart o Puccini firmadas por directores de cine como Werner Herzog, Michael Haneke o Carlos Saura. Bajo la influencia de la ópera en los cines, más que nunca, el cine parece volverse operístico y la ópera cinematográfica ${ }^{7}$.

\subsection{Una imagen alejada de la realidad}

La utilización de la imagen de los divos operísticos como reclamo cinematográfico es un recurso utilizado desde los inicios del siglo xx, que no siempre ha generado encuentros naturales entre ambas artes ${ }^{8}$. Ello es debido en gran parte a la fuerte dependencia existente, por tradición, entre las películas grabadas y la representación en vivo ${ }^{9}$. Aunque la audiovisualización de la ópera y su star system hayan posibilitado difundir el género musical, confiriéndole una mayor visibilidad y alcance social, la imagen audiovisual que tradicionalmente se ha dado de las estrellas de ópera ha quedado condicionada por las convenciones estéticas y sociales de este arte en los teatros ${ }^{10}$. Durante el siglo xx, de forma más o menos sistemática, en los medios de comunicación se ha alimentado una imagen de la ópera y sus divos algo descontextualizada, rígida, superficial y elitista. A través de las películas operísticas, los medios han trasladado también las convenciones sociales de este arte, consolidadas durante el siglo XIX, una época esplendorosa de la ópera en la que era el espectáculo más popular y concurrido de las ciudades europeas ${ }^{11}$.

Esta imagen alejada de la realidad hoy parece haber despertado la preocupación de los agentes operísticos. Como afirma Mia Bongiovanni, responsable de las retransmisiones de Metropolitan Opera House de Nueva York (2017), ante el cambio generacional que viven los públicos asistentes al espectáculo presencial, hoy la ópera replantea sus relaciones con los medios para conectar con nuevas y jóvenes audiencias, más familiarizadas ahora con el discurso audiovisual que con el operístico ${ }^{12}$. La industria lírica reactiva la audiovisualización de sus obras aprovechando la coyuntura generada por el negocio de la ópera en los cines. 


\section{Objetivos y metodología}

En este artículo nos proponemos analizar una de las iniciativas concretas de audiovisualización que la ópera ha llevado a cabo en el marco del negocio global que han generado sus retransmisiones cinematográficas: el cambio de imagen de los divos en los medios de comunicación, dirigido a lograr una mayor identificación con los públicos actuales y una mayor integración social.

\subsection{Objetivos}

Para entender la relevancia estratégica del star system lírico actual en los procesos mediáticos de diálogo con las audiencias, es importante estudiar la evolución que la imagen de las estrellas líricas ha sufrido desde los inicios del cine hasta nuestros días. En consecuencia, hemos desgranado nuestro propósito central en tres más específicos: 1) estudiar la imagen global de los cantantes de ópera ofrecida por el cine y la televisión desde sus orígenes, para 2) identificar los principales cambios que las retransmisiones de ópera en los cines han promovido en el star system operístico, a fin de 3) entender si esos cambios están contribuyendo a una actualización social del arte operístico.

\subsection{Metodología}

Para alcanzar los objetivos que nos hemos marcado, hemos dividido el análisis histórico en dos periodos: el primer periodo de estudio va desde los orígenes del cine hasta la aparición del Live in $H D$, en el año 2006; el segundo periodo que hemos estudiado corresponde a la década transcurrida desde ese año hasta la actualidad. En la estructura del trabajo nos referiremos a esas dos etapas como siglo $x x$ y siglo XXI. A pesar de que hemos seguido un criterio temporal en nuestro recorrido, atendiendo a los objetivos específicos que nos hemos marcado, los subapartados han quedado organizados según un criterio sistemático.

Tal como hemos recogido a lo largo de todo el artículo y en la bibliografía final, nuestro trabajo se ha apoyado en la consulta de una notable cantidad de fuentes bibliográficas. También hemos consultado numerosas fuentes publicadas por los teatros y organismos culturales desde el año 2012 hasta el año 2016 -tales como Opera Europa, Opera America, The Metropolitan Opera House de Nueva York o empresas intermediarias como Rising Alternative- $-{ }^{13}$.

Con respecto al estudio de las estrategias de márquetin de los divos de la ópera en los cines, durante los años 2013 y 2014 efectuamos el seguimiento de los canales de YouTube y las redes sociales de quince de los teatros más representativos en el contexto internacional, como The English National Opera, Los Ángeles Opera, Chicago Opera, Teatro Alla Scalla de Milan, The Sydney Opera o el Teatro Real de Madrid.

Asimismo, durante el verano de 2017 realizamos entrevistas personales a los responsables de comunicación de algunos de estos teatros; las mantenidas

[13] Pueden consultarse los sitios web oficiales de las instituciones: <http://www.opera-europa.org/es>; <https://www. operaamerica.org $>$; $<$ https:// www.metopera.org >; <http:// www.risingalternative.com $>$. Último acceso el 19 de marzo de 2018. 
[14] Durante el año 2012 nos reunimos con los equipos directivos de los dos teatros españoles de referencia: Gran Teatre del Liceu, en Barcelona, y Teatro Real de Madrid. En aquel momento entrevistamos a Joan Matabosch, Gerard Mortier y a Bárbara Berini, responsables, por aquel entonces, de la dirección de los teatros y de las retransmisiones de los espectáculos. Durante los meses de abril, mayo y junio de 2017 nos desplazamos hasta el teatro Los Ángeles Ópera y entrevistamos a su equipo directivo. Por otro lado, la entrevista a Mia Bongiovanni, responsable del departamento audiovisual del Metropolitan Opera House, tuvo lugar en las instalaciones del propio teatro, el 8 de octubre de 2017.

[15] Jaume Radigales, «La ópera y el cine: afinidades electivas», en La música en los medios audiovisuales, (Salamanca, Universitaria, 2007), pp. $59-84$.

[16] David Schroeder, Cinema's Illusions, Opera's Allure, p. 56.

[17] Gary Tomlinson, Canto metafísico: un ensayo sobre la ópera. (Barcelona, Idea Books, 2001). Jeremy Tambling, Opera, Ideology and Film (New York, St. Martin's Press, 1987).

[18] Jeremy Tambling, Opera, Ideology and Film.

[19] Jaume Radigales, Isabel Villanueva, «Le rôle de l'opéra dans le cinéma primitif: Étude des cas» (Performing New Media, 1895-1915. Twelfth International Domitor Conference, Brighton, UK, 2012). con Diane Bergman y John Nuckols, Vicepresidentes de Comunicación y de Financiación de Los Ángeles Opera, o con Mia Bongiovanni, responsable de las grabaciones y retransmisiones del Live in HD del Metropolitan Opera House de Nueva York, serían algunos ejemplos ${ }^{14}$.

\section{Recorrido histórico por el siglo xx: el cine desvirtúa la imagen del divo de ópera}

Cuando Norma, de Vincenzo Bellini, se representó por primera vez en el año 1831, las divas operísticas ya existían desde la primera mitad del siglo xvin: sopranos como Francesca Cuzzoni, Faustina Bordoni, Caterina Cavalieri, Maria Malibran, Giuditta Pasta o Giuditta Grisi se erigieron como estrellas de los escenarios de ópera durante aquel siglo. Después vendrían Jenny Lind, Adelina Patti, Regina Pacini, Nellie Melba o Rosa Ponselle. Pero fue Maria Callas quien unió el escenario con las páginas de la prensa rosa y quien puede ser considerada la primera diva moderna ${ }^{15}$, pues otorgó a las sopranos un fetichismo que han mantenido hasta hoy. Figuras como Montserrat Caballé, Edita Gruberová y, recientemente, Angela Gheorghiu o Renée Fleming son buena prueba de ello. El atractivo de la diva fue, en primer lugar, vocal. Con el cine se transformó en visual y fotogénico.

\subsection{En sus orígenes el cine utilizó a los divos como reclamo comercial}

Desde sus inicios, el cine aprovechó intuitivamente el atractivo lírico y las convenciones de la ópera. El canto, más concretamente, constituyó uno de los elementos que despertó mayor admiración entre creadores y audiencias: los cineastas asociaban el canto al glamur, la atención pública, la excentricidad y el acceso a la aristocracia. Asimismo, la fascinación de la sociedad por los cantantes provenía de un sueño que compartían con ellos: muchos divos de entonces provenían de clases sociales humildes y, con solo la voz, aparentemente poco trabajo y algo de suerte, habían conseguido encarnar algunas de las principales aspiraciones de la clase trabajadora, tales como el dinero y la fama ${ }^{16}$.

Atendiendo a razones artísticas, hasta la aparición del cine, el canto había constituido el principal elemento operístico capaz de provocar en el espectador un estado contemplativo desde el cual justificar emocionalmente cualquier irrealidad, hiperrealidad e incluso irracionalidad propuesta en la escena na$\operatorname{rrada}^{17}$. El nuevo espectáculo cinematográfico también necesitaba que el público pactara previamente con la irrealidad y, de forma natural, muchas de las primeras producciones utilizaron argumentos y estrellas de ópera para volver creíble el nuevo medio a ojos de aquellas audiencias que eran en esencia operófilas ${ }^{18}$. El cine musical operístico constituyó una de las tendencias de moda en la década de los años veinte del siglo pasado ${ }^{19}$. Citamos, a modo de ejemplo, la versión de Carmen de Bizet que Raoul Walsh dirigió en 1915, la producción 
de El Anillo del Nibelungo (Der Ring des Nibelungen), de Wagner, estrenada por Fritz Lang en 1924 (Los nibelungos, Die Nibelungen), o El Caballero de la Rosa (Der Rosenkavalier, Op. 59) llevada a la gran pantalla por Robert Wiene en 1925. Esas tres versiones muestran cómo el cine estaba colaborando, de manera más o menos consciente, en la construcción y magnificación de la imagen social de los cantantes de ópera ${ }^{20}$.

Durante la primera mitad del siglo xx, diversos divos iniciaron carreras estelares en la gran pantalla. Se les utilizaba como reclamo comercial de muchos títulos de cine, cuyo estreno se acompañaba con su actuación en directo ${ }^{21}$. Citamos como ejemplos: la versión de Carmen que Cecil B. de Mille estrenó en 1916, con la colaboración de Geraldine Farrar, cantante ya consolidada en teatros como el Metropolitan Opera House de Nueva York (Met); el Don Quijote de G.W. Pabst (Adventures of Don Quixote) que, en el año 1933, contó con el cantante bajo ruso Fiodor Chaliapin; o la producción, en el año 1932, de $L a$ novia vendida (Prodaná nevěsta), de Smetana, una reinterpretación realizada por el creador Max Ophüls (Die verkaufte Braut) en la que brillaba Jarmila Novotná, quien años más tarde intervendría en El gran Caruso (The Great Caruso, Richard Thorpe,1951) con Mario Lanza ${ }^{22}$.

La lista de cantantes que multiplicaron su fama y fortuna en la época del cine mudo creció significativamente con la llegada de la versión sonora. Algunos de los nombres más destacados fueron Lina Cavalieri, Anna Case, Enrico Caruso, Andrés de Segurola, Lawrence Tibbet, Lotte Lehmann, Mary Costa o Jan Kiepura.

En todas estas primeras películas, el movimiento estereotipado y el gesto afectado de sus actores y actrices tenía mucho que ver con la puesta en escena operística y otorgaba mayor valor al componente músico-teatral que al estrictamente cinematográfico ${ }^{23}$. Sin embargo, la evolución natural del lenguaje fílmico provocó un distanciamiento cada vez mayor entre la representación teatral y la audiovisual. Mientras el cine iba construyendo su propio modo de representación institucional, la ópera seguía queriendo satisfacer a sus públicos tradicionales. Como afirma Schroeder ${ }^{24}$, el hecho de contratar a un cantante para asumir un rol no cantado fue resultando inusual y forzoso, ya que muy pocos divos reunían toda la combinación de cualidades exigidas frente a la cámara: habilidad dramática para conseguir telegenia sin perder la flexibilidad gestual propia del canto, personalidad fascinante, apariencia física y popularidad. A excepción de casos como la reconocida capacidad actoral de Geraldine Farrar, Mario Lanza o, incluso, María Callas —en la versión de Medea dirigida, en 1969, por Pier Paolo Pasolini-, muy pocos cantantes obtuvieron éxito al ser contratados como actores. En las últimas décadas del siglo xx, probaron suerte, con más o menos fortuna, Ruggero Raimondi, Plácido Domingo o José Van Dam.

Tanto las directrices escénicas e interpretativas de estas primeras películas, orientadas a satisfacer los gustos de un género musical considerado entonces en declive, como la incapacidad que presentaban sus artistas para
[20] Richard Fawkes, Opera on Film, (London, Gerald Duckworth \& Co, 2000).

[21] Jaume Radigales, «La ópera y el cine: afinidades electivas», pp. 59-84.

[22] Robert Christiansen, Prima Donna: A History, (New York, Penguin Books, 1984).

[23] Jaume Radigales, Isabel Villanueva, «Le rôle de l'opéra dans le cinéma primitif: Étude des cas».

[24] David Schroeder, Cinema's Illusions, Opera's Allure, p. 296. 
adaptarse al desarrollo y exigencias del nuevo medio de masas generaron una primera imagen algo sofisticada y antinatural de los divos a través de la ficción audiovisual. Este distanciamiento ayudó a que, desde sus orígenes, se estableciese una relación asimétrica entre las artes: el cine impulsó el fenómeno de masas operístico sin conseguir que la ópera lograse aportar protagonistas al star system cinematográfico, que surgía como propio y exclusivo de la gran pantalla. Sin parecer entender la capacidad comunicativa que presentaba el nuevo medio cinematográfico, la ópera perdía una primera oportunidad de conectar con públicos lejanos a su mundo.
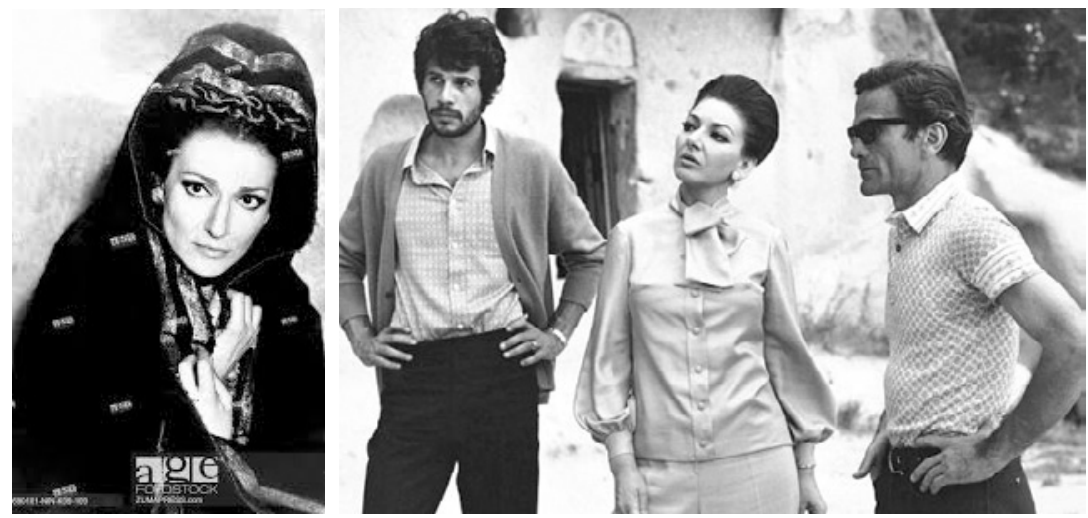

Fig. 1. Capturas de la filmación de Medea (Pier Paolo Pasolini, 1969) con María Callas como protagonista de la película.

\subsection{El cine estereotipa la imagen de la ópera}

De acuerdo con Richard Fawkes ${ }^{25}$, diversas tipologías de productos operísticos audiovisuales que se asentaron en el mercado durante la segunda mitad del siglo xx contribuyeron, en mayor o menor medida, a agudizar la primitiva imagen social del cantante lírico.

$\mathrm{Al}$ estar todavía ligada a las convenciones de la representación teatral heredadas del siglo XIX, las manifestaciones de la ópera en la gran pantalla solieron transmitir una imagen distante y superficial del mundo de la lírica y sus estrellas ${ }^{26}$. Es un fenómeno que se advierte, por ejemplo, en la práctica de

[25] Richard Fawkes, Opera on Film, pp. 171-209.

[26] Véase Jeremy Tambling, Opera, Ideology and Film. John Roselli, «La ópera como acontecimiento social», en Historia ilustrada de la ópera (Barcelona, Paidós Ibérica, 1998), pp. 450-482. imitar en pantalla la estética grotesca y acartonada propia de las escenografías del teatro, incluso en las óperas filmadas fuera de los mismos. Citamos, como ejemplo, la producción en el año 1953 de Aida de Verdi, dirigida por Clemente Fracassi, o las numerosas adaptaciones operísticas llevadas a cabo por el director Carmine Gallone a lo largo de su carrera.

Además, en la mayoría de las ocasiones, el mundo de los cantantes y su star system se ha retratado desde el glamur, la obsesión, la grandilocuencia o, incluso, la burla, como bien puede advertirse en la paródica versión que los 
hermanos Marx, dirigidos por Sam Wood, protagonizaron en Una noche en la ópera (A Night at the Opera), en el año 1935; o en la producción de Fitzcarraldo, dirigida por Werner Herzog en 1982. En estas y otras muchas películas la tendencia ha sido la de otorgar a las estrellas líricas roles de cierto glamur y grandiosidad, pero también de cierta simplicidad psicológica y falta de humanismo: con el fin de ponerles en situación de éxito, normalmente solo se les ha permitido mostrar su faceta más virtuosística: el canto ${ }^{27}$.

Múltiples factores parecen explicar esa recreación distorsionada, sofisticada y grotesca que el cine ha ofrecido de la ópera. La mayoría de ellos pueden quedar recogidos en tres tendencias de grabación que, durante la segunda mitad del siglo xx, contribuyeron a alejar la realidad operística de la idea que de ella se construían los públicos: 1) el respeto por la tradición teatral, 2) los procesos de filmación específicos de este género musical y 3) la proliferación del biopic lírico.

En primer lugar, las filmaciones de ópera durante el siglo xx quedaron inscritas dentro de la tradición de los teatros de ópera; muchas veces, el espacio físico donde se producía la representación también formaba parte de la película, de forma que el uso de planos de la orquesta o el director ayudaban a crear una estilización no natural del hecho filmado. Separaban al espectador de la narración y le acercaban al pathos musical. Las óperas documentadas, por ejemplo, difícilmente pudieron ser entendidas por un público que desconoce la tradición del espectáculo presencial ${ }^{28}$.

En segundo lugar, los propios procesos de filmación de las óperas han generado cierta falta de verosimilitud artística, sobre todo en lo que se refiere a la filmación del canto ${ }^{29}$. Desde el punto de vista estético, la utilización de los primeros planos en una interpretación solista se considera desagradable y, para los públicos más operófilos, intrusivo, al permitir recrearse en el gesto forzado del cantante e interferir en la narración musical ${ }^{30}$. El primer plano resulta más forzado todavía en las películas operísticas propiamente narrativas, como las de tipo television opera u ópera filmada ${ }^{31}$. En ellas se prescinde de la grabación en el propio teatro y, por lo tanto, se pierde la alusión al espectáculo presencial y la consecuente capacidad de aceptación del artificio gestual dentro de las convenciones del arte ${ }^{32}$.

En estos productos se ha recurrido con frecuencia al playback de actores y cantantes, con el fin de conseguir mayor verosimilitud interpretativa cuando se escenificaban en espacios abiertos las arias y los conjuntos vocales. Apuntamos tres ejemplos: la versión cinematográfica de Parsifal de Wagner que Hans-Jürgen Syberberg dirigió en 1982, La Traviata de Verdi dirigida el mismo año por Franco Zeffirelli, con estrellas como Teresa Stratas y Plácido Domingo, o la inter-
[27] David Schroeder, Cinema's Illusions, Opera's Allure.

[28] Véase Jeremy Tambling, Opera, Ideology and Film. Youssef Ishaghpour, Opéra et théâtre dans le cinéma d'aujourd'hui.

[29] Christopher Morris, «Digital Diva: Opera on video» (Opera Quarterly, 26, 2010), pp. 96-119.

[3o] Robert Donington, «Close Ups v. Opera», (The Musical Times, vol. 129, 1988) p. 281.

[31] Xavier Bové, «Entrevista realizada por los autores al departamento audiovisual y de documentación del Gran Teatre del Liceu», (Barcelona, mayo de 2011).

[32] Paul Heyer, «Live from the Met: Digital Broadcast Cinema, Medium Theory, and Opera for the Masses», (Canadian Journal of Communication, vol. 33, 2008), pp. 591-6o.
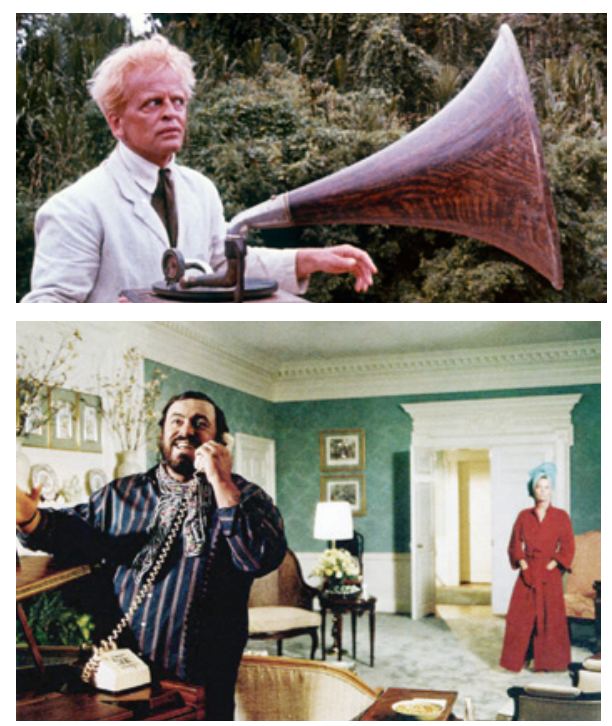

Fig. 2. Fotogramas de las películas Fitzcarraldo (Werner Herzog, 1982) y Sí, Giorgio (Yes, Giorgio, Fraklin J. Schaffner, 1982). 
[33] Jaume Radigales, «Playback problems when Filming Opera for the Screen: Two Case Studies», pp. 115-127.

[34] Marcia Citron, «Subjectivity in the Opera Films of JeanPierre Ponnelle» (The Journal of Musicology, 1994, vol. 22), pp. 203-240.

[35] Walter. H. Auden, «Some Reflections on Opera as a Medium», (Tempo, New Series, vol. 20, 1951), pp. 6-10. pretación de Luciano Pavarotti y Edita Gruberová en el Rigoletto verdiano que Jean-Pierre Ponelle estrenó en $1983^{33}$. Además del playback, se han ido repitiendo otros recursos para evitar el primer plano del cantante: la recreación de flashbacks visuales en el momento de la interpretación del aria y la simulación del monólogo interior. Aunque todos ellos han tratado, en el fondo, de superar el estatismo narrativo del discurso operístico, también han evitado mostrar la cara más real, cruda y física del trabajo del artista, reforzando una imagen de los divos más cercana a la mitología que a las acciones humanas.

Cabe hacer referencia a otras problemáticas adicionales relacionadas con los procesos de filmación del canto de los divos: la cualidad estática de la escenografía tradicional operística, la ausencia de libertad interpretativa y de movimientos actorales al quedar condicionados por la música, la rigidez facial que exige la mirada a la cámara, la lentitud audiovisual de ciertos pasajes musicales como las oberturas o la excesiva duración de las óperas. Todos ellos son factores altamente determinantes en la consecución de una fidedigna imagen del arte operístico y de sus creadores ${ }^{34}$.

Debe mencionarse, en tercer y último lugar, la influencia que el biopic lírico ejerció sobre el imaginario social acerca de los divos del canto. Durante el siglo xx, el biopic se inspiró en la vida de cantantes y compositores para producir películas con fines comerciales. El Gran Caruso, que Richard Thorpe estrenó en 1950, La muerte de María Malibrán (Der Tod der Maria Malibran), dirigida por Werner Schroeter en 1971, o las tres versiones de la vida del célebre tenor Julián Gayarre producidas por el cine español son tres buenos ejemplos (El canto del ruiseñor [Carlos San Martín, 1932], Gayarre, [Domingo Viladomat, 1959]; Romanza final [José María Forqué, 1986]). Aunque casi todas las películas parten de biografías reales documentadas, han tendido a mostrar, de una manera subjetiva y sensacionalista, las personalidades más carismáticas y extravagantes de los divos. Como si contasen con un guion preestablecido, en todas las películas se destaca la genialidad y el virtuosismo innato de sus voces. En ellas también se dibujan, por lo general, vidas privadas vacías y difíciles, cargadas de acontecimientos dramáticos o vicisitudes amorosas. Es el caso de, por ejemplo, Callas Forever (2002), de Franco Zeffirelli; Sí, Giorgio (Yes, Giorgio), encarnada por Pavarotti y dirigida por Franklin Schaffner en 1982; o la historia de Farinelli, il Castrato, estrenada en 1994 y dirigida por Gérard Corbiau.

Salvo valiosas excepciones, como la versión de La Flauta Mágica (Die Zauberflöte) de W.A. Mozart rodada por Ingmar Bergman en el año 1974 (Trollflöjten), el Parsifal de Syberberg o el Don Giovanni mozartiano dirigido por Joseph Losey en 1979, la mayor parte de los productos audiovisuales realizados desde los años cincuenta ha contribuido a crear una imagen social distorsionada de la realidad operística. Las técnicas empleadas en la filmación no han ayudado a mejorar la verosimilitud narrativa de los personajes de ópera, los cuales ya de por sí son simples y arquetípicos ${ }^{35}$. A través de la ficción melodramática, el mundo de las estrellas se ha retratado a sí mismo como irreal e inalcanzable. Ha 
impedido al espectador conocer facetas humanas de la vida del cantante mediante las que hubiera podido sentirse identificado y, sobre todo, mediante las que hubiera podido sentir el deseo de aprender y compartir el arte operístico.

\section{Recorrido histórico por el siglo xxI: hacia la creación del cantante mainstream}

El recorrido por el siglo xx muestra que la ópera entró en el siglo xxi con un problema de actualización mediática. A ojos de muchos públicos representa un género musical desconocido, lejano y propio de otra época ${ }^{36}$ no solo porque, debido a su tradición, la ópera haya sido considerada un arte inmovilista, sino porque, además, necesita que los públicos deseen aprender la complejidad que, en tanto que síntesis de artes, posee ${ }^{37}$.

A partir del año 2000, conscientes de esa realidad y afectados por las transformaciones que la digitalización ha provocado en las economías culturales, los teatros han promovido un cambio aperturista hacia la creación y fidelización de nuevas audiencias ${ }^{38}$. Replantean sus estrategias de comunicación teniendo ahora en cuenta múltiples fenómenos como: la naturaleza mediática del consumo de ocio de los jóvenes, la pantallización global que ha invadido las vidas públicas y privadas, el uso de tecnología digital capaz de retransmitir la ópera en calidad óptima fuera de los escenarios o la incorporación, en los procesos de producción, de estrategias publicitarias propias del márquetin en las artes ${ }^{39}$.

Afectada por tales tendencias sociológicas, es hoy cuando la ópera centra de nuevo sus estrategias comunicativas en el cine y los medios digitales. Persigue cambiar la imagen distante que los públicos, en especial los jóvenes, han construido de ella ${ }^{40}$. Así, en el siglo xxı la industria de la ópera está avanzando en la difusión global de su espectáculo en formato audiovisual: se consolida el negocio de la ópera en los cines; surgen nuevas plataformas de consumo en la red, tales como el vídeo a la carta o las retransmisiones vía streaming; se comercializan versiones para operófilos coleccionistas en DVD; o se crean mediatecas virtuales de consulta de vídeos y aplicaciones para dispositivos móviles ${ }^{41}$.

En los últimos diez años, muchos de los productos y servicios audiovisuales de la lírica se han consolidado como nuevas ventanas de explotación comercial. Todos ellos se generan a partir de (y dependen de) la grabación del espectáculo original en el teatro ${ }^{42}$. Resulta lógico, por tanto, que los procesos de producción de la ópera en escena se adapten paulatinamente a las nuevas exigencias provocadas por los nuevos mercados, en especial por las retransmisiones en los cines ${ }^{43}$.
[36] Ann Laenen, Why Opera Education? a RESEO research report (RESEO, 2003).

[37] Véase Umberto Eco, Obra abierta, (Barcelona, Planeta-De Agostini, 1985); Janice Smith, «Opera as an Interdisciplinary Art» (Music Educators Journal, Vol. 79, 1992), pp. 21-61.

[38] Bárbara Berini, «Entrevista realizada por los autores al departamento audiovisual y de documentación del Gran Teatre del Liceu» (Barcelona, mayo de 2011).

[39] Véase Guilles Lipovetsky, Jean Serroy, La pantalla global. Cultura mediática y cine en la era hipermoderna. (Barcelona, Anagrama, 2009); Martin Cuadrado, «La gestión de marketing en las entidades escénicas. Una evidencia empírica» (DYO, vol. 25, 2001), pp. $80-87$.

[40] Véase Roger Silverstone, Television and Everyday Life, (New York, Routledge, 1994); Jose Alberto García-Avilés, «La comunicación ante la convergencia digital» (Signo y Pensamiento, vol. 54, 2009), pp. 102-113.

[41] Véase Antonio De Diego, «Nuevas estrategias comunicativas en ópera por la inclusión del "making of" en los DVDs. International Workshop on Opera y Video» (Universidad Politécnica de Valencia/Institut Valencià de la Música, 2010); Julie Annie Carroll, Marcus Foth \& Barbara Adkins, "Traversing urban social spaces: how online research helps unveil offline practice», en International handbook of internet research (New York, Springer Netherlands, 2009), pp. $147-158$.

[42] Véase Christopher Morris, «Digital Diva: Opera on video» (Opera Quarterly, 26, 2010), pp. 96-119; Jennifer Barnes, Television Opera: The fall of Opera commissioned for Television. (Woodbridge, The Boybell Press, 2003).

[43] Se entiende que las retransmisiones de ópera no solo están modificando los procesos y los equipos digitales en las salas de cine y teatros, sino también la aportación de los diseñadores y directores de escena, así como la colaboración de los agentes artísticos. El Live in HD también modifica la ideación de los públicos, ahora más compleja y compuesta por una audiencia presencial en el teatro y una audiencia cinematográfica de escala mundial. 


\subsection{Cantantes integrales que actúan como embajadores de los teatros}

Si por tradición la lírica había apostado principalmente por las voces, en el siglo xxı los directores de escena imponen castings complejos en los que introducen pruebas de cámara para encontrar, preferencialmente, físicos atractivos para el medio audiovisual ${ }^{44}$. Estos cambios han ido influyendo en la figura del divo de ópera, hoy más cercana que nunca al márquetin propio del star system cinematográfico y su continua retroalimentación mediática. De forma paradójica, hoy es la ópera la que se inspira en el cine e imita sus modelos comunicativos, a fin de ganar seguidores. Divos del siglo xxı, tales como Renée Fleming, Anna Netrebko, Angela Georgiu, Natalie Dessay, Rolando Villazón, Juan Diego Flórez o Roberto Alagna han tenido que crecer como artistas integrales para cumplir las exigencias del nuevo cantante global. Dichas exigencias van más allá de sus aptitudes musicales: ponen la voz al servicio de requisitos visuales e interpretativos para satisfacer los gustos de las audiencias mediáticas.

A su vez, las retransmisiones de ópera en las salas cinematográficas están construyendo una nueva imagen de los cantantes gracias a la incorporación de recursos mediáticos propios de los espectáculos televisivos y los canales online de música. Como forma de entretenimiento, por ejemplo, en los intermedios de las representaciones se emiten entrevistas realizadas a los cantantes. Esas declaraciones constituyen una relevante herramienta de educación.

[44] John Nuckols, «Entrevista realizada por una de las autoras al Vicepresidente de asuntos económicos de Los Angeles Opera» (Los Ángeles, 10 de mayo de 2017).

[45] Áine Sheil, «The opera director's voice: DVD 'Extras' and the question of authority", en Opera and video. technology and spertatorship. (Berna, Peter Lang, 2012), pp. 129-150. Con ellas, el público aprende el valor de la ópera como arte colectivo mucho más complejo de lo que pudiera apreciar solo con la interpretación vocal. La opinión de los cantantes, directores y escenógrafos ayuda a contextualizar el sentido de la obra en la actualidad ${ }^{45}$. Al mismo tiempo, también en esos entreactos, resulta cada vez más frecuente ver a los divos ejerciendo de periodistas con sus compañeros de reparto. Reneé Fleming o Plácido Domingo son algunas de las superestrellas contratadas por el Met Live in HD para entretener en los descansos a sus miles de fans virtuales, como puede comprobarse en la figura 3 .
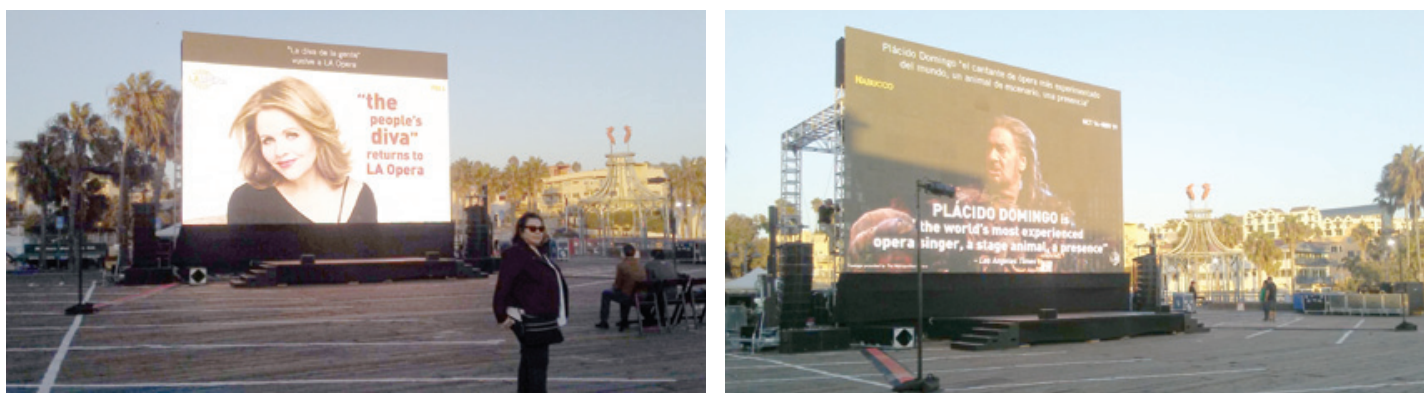

Fig. 3. Fotografías del descanso de una representación en el muelle de Santa Mónica Beach de Los Ángeles Ópera en agosto de 2017. 


\subsection{Patrocinio y product placement de las marcas de lujo con los divos}

Otro de los factores que han influido en la creación de esta imagen institucionalizada de los divos es la relación que ahora establecen con los inversores publicitarios mundiales. La alianza comercial entre los cantantes y las marcas tradicionalmente ha permitido que los atributos del mundo de la ópera se asocien directamente a bienes de lujo como joyas, relojes, perfumes o coches de alta gama. Desde los años noventa del pasado siglo, el patrocinio de cantantes líricos ha logrado generar una imagen de exclusividad de estas marcas en sus mercados objetivo y, adicionalmente, atraer a públicos cinéfilos interesados en la cultura del arte. En aquellos años, el patrocinio publicitario se materializaba en las campañas de una forma explícita, como bien puede apreciarse en la figura 4 .

Veinte años después, la constante presencia audiovisual de la ópera en los medios no ha hecho sino aumentar el interés de las marcas de lujo por el patrocinio de las estrellas líricas como medida de penetración en audiencias cinematográficas. En los últimos años, ha resultado muy común presenciar a los divos en estrategias comerciales que acompañan a las temporadas de los teatros, como pueden ser las campañas publicitarias mundiales de los cines o las representaciones corporativas en actos públicos relacionados con la industria del entretenimiento. Apuntamos, como ejemplo, la alianza inseparable de la imagen de Reneé Fleming con el Metropolitan Opera House de Nueva York y la discográfica Decca, tras firmar un contrato millonario a principios de siglo. A fin de conseguir una mayor penetración en el mercado global, ahora las marcas de lujo parecen apostar por estrategias publicitarias como el product placement, algo más discretas que el patrocinio explícito de los primeros años. Sin renunciar a la exclusividad que supone el mundo glamuroso de la ópera para estas marcas, las campañas más actuales recurren al emplazamiento de los productos de lujo en las películas, óperas filmadas, biopics o documentales en los que colaboran las grandes voces del canto. El product placement alrededor de la vida privada y pública de las estrellas también constituye una práctica comercial heredada de las industrias del cine y de la música pop. Permite que las marcas se asocien de una manera natural a los mundos afectivos de estos cantantes, generalmente relacionados con valores ya citados como el glamur, el exotismo, la fama y el lujo.

Precisamente, gracias al boom de la audiovisualización operística, el interés de marcas como Cartier, Rolex, Channel, Mercedes Benz o Ferrari ha aumentado. En el sistema comercial en el que se desarrollan hoy las actividades de los teatros, los contratos de las estrellas incorporan cláusulas de grabación y derechos de emisión que hace diez años no existían ${ }^{46}$. Las retransmisiones de la ópera del Met Live in HD para los cines han hecho que el star system operístico no constituya un fenómeno aislado desde un punto de vista publicitario, sino que hoy quede también integrado dentro de la estrategia comercial de los 

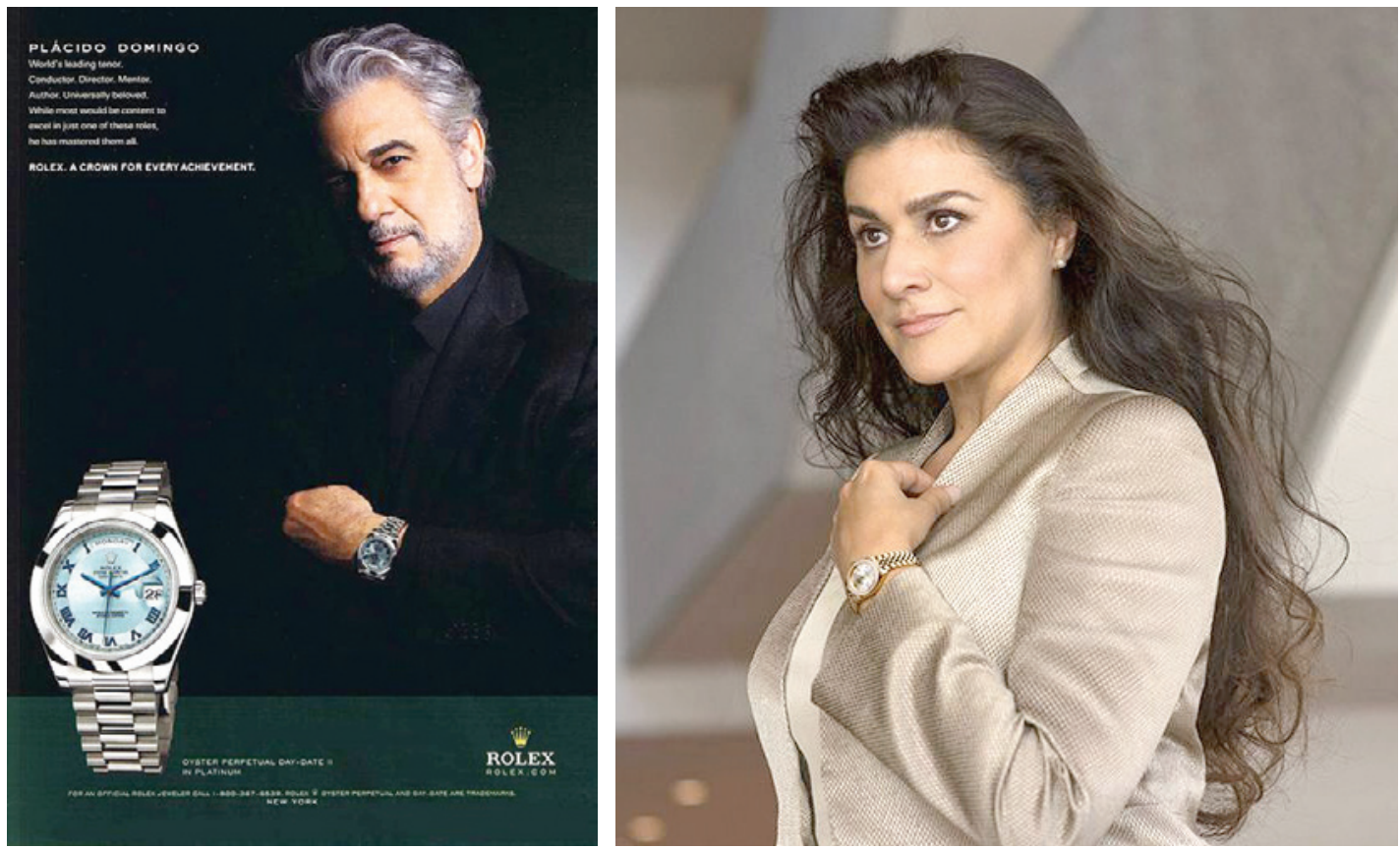

Fig. 4. Ejemplos de alianza comercial de cantantes líricos con la marca Rolex, a finales de los años noventa. Imágenes extraídas de la página oficial de Rolex

[46] John Nuckols, «Entrevista realizada por una de las autoras al Vicepresidente de asuntos económicos de Los Angeles Opera» (Los Ángeles, 10 de mayo de 2017).

[47] Xavier Bové, «Entrevista realizada por los autores al departamento audiovisual y de documentación del Gran Teatre del Liceu», (Barcelona, mayo de 2011). espectáculos ${ }^{47}$. Para la mayor parte de los cantantes, la participación en las retransmisiones supone una meta aspiracional por la posibilidad que les brinda de engrandecer su fama internacional. Además de como cantantes, pueden colaborar con ellas como embajadores del propio teatro en otras plataformas. Aunque a muchos de los divos les molesta la constante presión que la filmación de sus interpretaciones ejerce, también reconocen que la plataforma publicitaria a gran escala que representa es capaz de aumentar significativamente el número de sus fans. Gracias a la ópera en los cines, consiguen integrarse en un negocio y en un tipo de contratación que no acaba con la simple grabación de la representación en directo, sino que, muchas veces, se extiende a multiplicar los contratos con otras marcas de lujo. De esta manera, la estrategia de negocio operístico incorpora iniciativas transmediáticas con sus divos, orientadas a aumentar los beneficios económicos y mejorar la visibilidad mundial de los espectáculos.

\subsection{Las redes sociales humanizan y acercan la imagen del divo}

Es en las redes sociales creadas en torno a las representaciones en los cines donde el star system operístico parece estar adquiriendo una nueva dimensión social. A través de sus cuentas en Facebook, Twitter o Instagram, los divos y divas del espectáculo se comunican directamente con los públicos, antes y después de las funciones en streaming, y generan auténticos colectivos virtuales en torno a sus figuras. A diferencia de las cuentas oficiales de los teatros, 

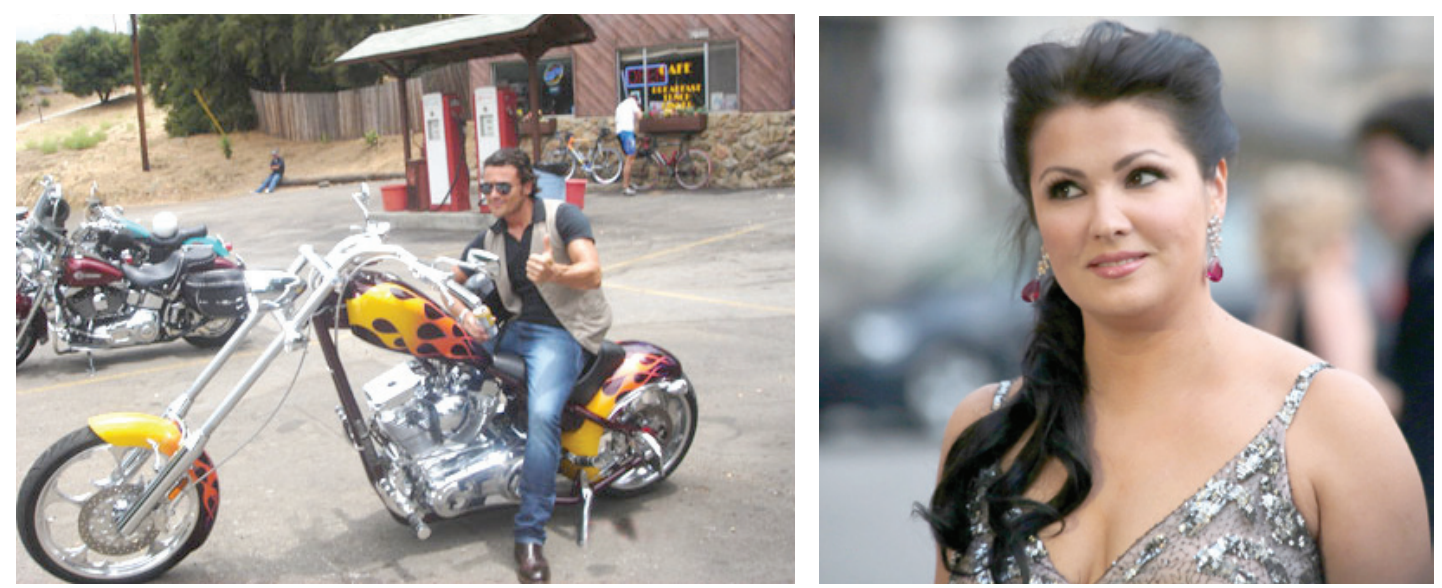

Fig. 5. Imágenes de la campaña de product placement protagonizada por el tenor Vitorio Griggolo para la marca Harley Davidson y de Anna Netrebko para la marca Swarovski.

los divos otorgan a las redes un uso mucho más personalizado. Responden a las inquietudes de los fans y cuelgan opiniones musicales sobre su trabajo en los teatros. A través de un acto tan sencillo como es participar activamente en las redes, la ópera está encontrando la manera de crear comunidades virtuales capaces de intercambiar conocimientos, relaciones, deseos o recuerdos asociados ahora a la nueva versión que los medios ofrecen de las estrellas líricas. Gracias a internet los divos proyectan una imagen más actual, humanizada y social de sí mismos y, en consecuencia, también de la ópera, lo cual provoca un visible interés compartido y contribuye a multiplicar el número de seguidores. La imagen cercana que los divos muestran en las redes compensa la magnificación de sus figuras en la gran pantalla. Se acercan a los mundos afectivos de los públicos, se convierten en referentes y se muestran conectados y comprometidos con las inquietudes más humanas. Así, siguiendo estrategias análogas a las que la industria del cine pone en práctica en internet y en las redes sociales con sus propias estrellas, los divos están consiguiendo no solo transformar su propia imagen, ahora más terrenal, sino actualizar el mundo de la ópera, suscitar el interés de los públicos y, por extensión, el de los inversores publicitarios.

\section{Conclusiones}

Tal como muestra el recorrido en dos grandes etapas que hemos realizado, a lo largo de su historia la ópera ha aprovechado la fascinación por el canto para apoyar sus modos de representación - basados en tradiciones decimonónicas ligadas al teatro- en el tejido de un star system lírico, algo que le ha aportado multitud de seguidores. En parte gracias a sus divos, la ópera ha consolidado nuevas vías de difusión de su espectáculo fuera de los escenarios. Desde los inicios del cine hasta nuestros días, el arte operístico ha utilizado la gran pantalla como vía de comunicación de sus convenciones con la sociedad. 

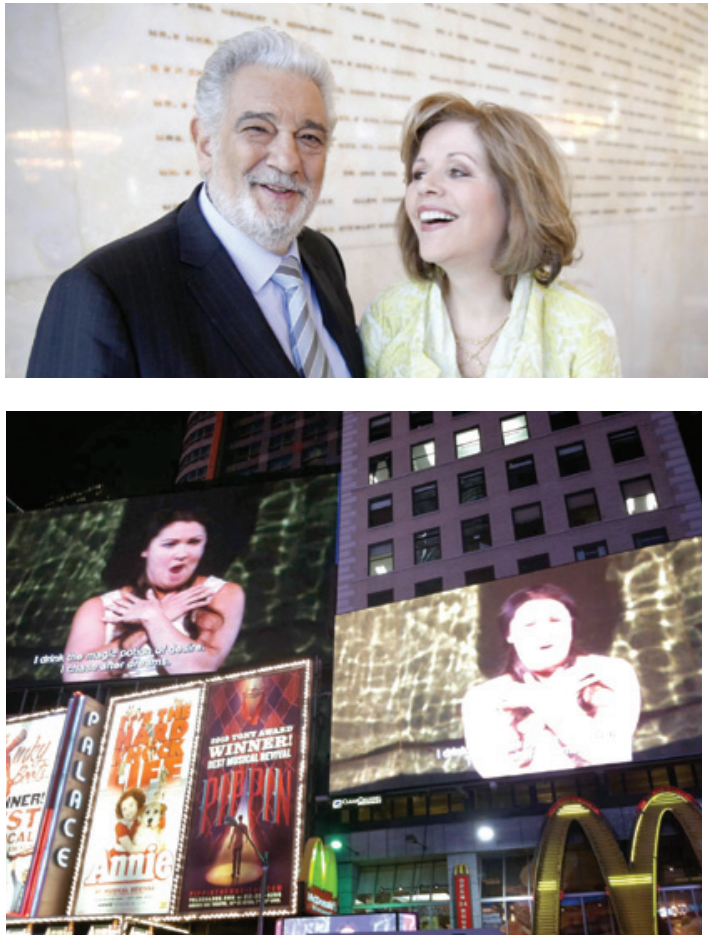

Fig. 6. Fotografías de los divos Plácido Domingo, Reneé Fleming y Anna Netrebko actuando como embajadores de los teatros a través de los distintos medios audiovisuales
Por otro lado, el universo lírico y su star system no han constituido para el cine más que una fuente intermitente de recursos temáticos, narrativos, artísticos y comerciales. A la hora de difundir la ópera y el mundo operístico, el medio cinematográfico ha expresado el drama musical casi de forma exclusiva a partir de tópicos. Los ejemplos expuestos ayudan a entender el modo en que el medio cinematográfico ha retratado a los divos: como figuras glamurosas, irreales, lejanas y artificiosas.

Como hemos podido comprobar en la investigación, el éxito actual de las retransmisiones operísticas en directo en las salas de cine significa la consumación de los tradicionales intentos de relación del arte musical operístico con los medios de comunicación. La ópera vía streaming disfrutada en una sala de cine, a pesar de distinguirse claramente del espectáculo original, consigue reinterpretarlo de forma sincera, respetuosa y auténtica, gracias a quedar firmemente vinculado a él. El Live in HD constituye un nuevo evento mediático que genera audiencias mundiales y un beneficio anual de millones de dólares. Resulta lógico que el star system de los divos quede integrado en la extensión comercial que ofrecen las retransmisiones de ópera en los cines. El divo vuelve a la gran pantalla, esta vez de una forma mainstream, integral y sofisticada.

Como se ha podido comprobar a lo largo de nuestro trabajo, si bien durante más de cien años el cine ha recurrido al género de la ópera para lograr beneficios comerciales, es el propio arte operístico quien hoy toma conciencia de la oportunidad que le brinda la comunicación digital inmediata, las retransmisiones en tiempo real y la posibilidad de descentralizarse que le ofrecen las salas cinematográficas. Las iniciativas audiovisuales, también con sus divos, constituyen hoy una de las principales estrategias de promoción del arte a escala global.

En concreto, lo que parece cambiar tras el Live in $H D$ es la estrategia de márquetin y publicidad con los divos. Por un lado, las retransmisiones de ópera en la gran pantalla engrandecen su fama y les convierten en superestrellas mundiales. Por otro lado, la descentralización que ofrecen los cines facilita un acceso más frecuente a los espectáculos, de modo que aumenta la presencia de los divos en espacios cotidianos. Si la ópera quiere dialogar con los públicos, aquel márquetin que ella centra en su star system debe potenciar las dos facetas de los divos mainstream; al mismo tiempo, debe quedar integrado de forma indivisible 
en las carreras de estas estrellas, a fin de que permita a estas últimas aumentar su número de seguidores y facilitar el encuentro con las grandes marcas.

Este márquetin comienza en los teatros y se extiende a las miles de pantallas que hoy habitan los cines multisala. Pero no se limita solo a ellas. Gracias al desarrollo de estrategias comerciales más discretas, como el product placement o el branded content, vinculadas a las retransmisiones en los cines, el star system está adquiriendo un aire más actual, urbano y cercano a la realidad de los espectadores. Por lo tanto, puede decirse que la ópera consigue, en parte gracias a los divos, actualizar su imagen.

La dimensión más cercana y terrenal de los divos se cultiva también en las redes sociales. En ellas, los cantantes se muestran comprometidos con temas de actualidad, expresan sus opiniones y publican vídeos personales. También aprovechan las comunidades virtuales para dialogar con los jóvenes y para estimular el intercambio natural de sus deseos e inquietudes. A través de un mayor impulso de estas estrategias lideradas por sus estrellas, la ópera podría suscitar auténticas implicaciones personales de las audiencias con su mundo y despertar en ellas el deseo de aprender su arte.

Por todo lo expuesto en este trabajo, puede decirse que, apoyándose en el Live in $H D$, la ópera, con sus divos, crea referentes capaces de mostrarse conectados y comprometidos con las inquietudes más humanas. El aumento de la presencia audiovisual de los divos, favorecida por el nuevo modelo institucional, está eliminando gradualmente los aspectos elitistas propios de otro siglo. Instaura un nuevo tipo de figuras de referencia que, ahora sí, además de ser atractivas e incluso exclusivas, están conectadas con la actualidad y alejadas del exclusivismo social que ostentaban en el pasado. El divo en la gran pantalla está consiguiendo, en definitiva, que la ópera conecte con audiencias no operísticas, pero culturalmente activas, a las que en no pocas ocasiones logra atraer hasta el espectáculo en vivo.

\section{FUENTES PRIMARIAS}

Berini, Bárbara, «Entrevista realizada por los autores al departamento audiovisual y de documentación del Gran Teatre del Liceu» (Barcelona, mayo de 2011)

Bongiovanni, Mia, «Entrevista realizada por una de las autoras a la responsable de las retransmisiones en HD para los cines del Metropolitan Opera House de Nueva York», (Nueva York, 6 de octubre de 2017).

Bové, Xavier, «Entrevista realizada por los autores al departamento audiovisual y de documentación del Gran Teatre del Liceu», (Barcelona, mayo de 2011).

Nuckols, John, «Entrevista realizada por una de las autoras al Vicepresidente de asuntos económicos de Los Angeles Opera» (Los Ángeles, 10 de mayo de 2017).

\section{BIBLIOGRAFÍA}

Adorno, Theodor, Escritos musicales I-III. (Madrid, Ediciones Akal, 2006).

Álvarez-Monzoncillo, José María, Cine: riesgos y oportunidades se equilibran ante el 
cambio digital. Hacia un nuevo sistema mundial de comunicación. Las industrias culturales en la era digital. (Madrid, Gedisa, 2003), pp. 85-110.

Auden, Walter. H., «Some Reflections on Opera as a Medium», (Tempo, New Series, vol. 20, 1951), pp. 6-10.

Barnes, Jennifer, Television Opera: The fall of Opera commissioned for Television. (Woodbridge, The Boybell Press, 2003).

Benjamin, Walter, «La obra de arte en la época de su reproductibilidad técnica», en Discursos interrumpidos I, (Buenos Aires, Taurus, 1989).

Bourre, Jean, Opéra et Cinema, (París, Artefact, 1987).

CARroll, Julie-Anne; Foth, Marcus \& Adkins, Barbara, «Traversing Urban Social Spaces: How Online Research Helps Unveil Offline Practice», en International handbook of internet research (New York, Springer Netherlands, 2009), pp. 147-158.

Christiansen, Robert, Prima Donna: A History, (New York, Penguin Books, 1984).

Citron, Marcia, «Subjectivity in the Opera Films of Jean-Pierre Ponnelle» (The Journal of Musicology, vol. 22, 1994), pp, 203-240.

-, Opera on Screen (London, Yale University Press, 2000).

CuAdRAdo, Martín, «La gestión de marketing en las entidades escénicas. Una evidencia empírica» (DYO, vol. 25, 2001), pp.80-87.

De Diego, Antonio, «Nuevas estrategias comunicativas en ópera por la inclusión del "making of" en los DVDs. International Workshop on Opera y Video» (Universidad Politécnica de Valencia/ Institut Valencià de la Música, 2010).

Donington, Robert, «Close Ups v. Opera», (The Musical Times, vol. 129, 1988), p. 281.

Eco, Umberto, Obra abierta, (Barcelona, Planeta-De Agostini, 1985).

FAwKES, Richard, Opera on Film, (London, Gerald Duckworth \& Co, 2000).

GarCíA-Avilés, Jose Alberto, «La comunicación ante la convergencia digital» (Signo y Pensamiento, vol. 54, 2009), pp. 102-113.

García-SANTAMARía, Víctor, «El futuro de la exhibición. La transformación de los complejos de cine en complejos de ocio», (Telos, vol 78, 2009).

GoRDILLo, Irene, «La hibridación en las nuevas formas dramáticas y espectaculares del siglo XXI» (Icono14, vol, 10, 2008), pp. 1-20.

HeYER, Paul, «Live from the Met: Digital Broadcast Cinema, Medium Theory, and Opera for the Masses», (Canadian Journal of Communication, vol. 33, 2008), pp. 591-60.

Huertas, Fernando, «El futuro digital del cine». (Telos, Vol. 51, 2002), pp. 78-89.

Ishaghrour, Youssef, Opéra et théâtre dans le cinéma d'aujourd'hui, (París, La Différence, 1995).

IzquiERDo, Jessica, «El impacto de la tecnología en la exhibición cinematográfica: el lento camino a la sala digital» (Revista Latina de Comunicación Social, vol. 12, no 64, 2009).

LACASA, Iván; Villanueva, Isabel, «La digitalización audiovisual de la ópera. Nuevos medios, nuevos usos, nuevos públicos» (Telos, vol 88, 2011), pp. 65-74.

-, «Actualización de la ópera y sus nuevos modelos de comunicación digital», (El Profesional de la Información, vol 21, 2012), pp. 413-418.

LAENEN, Ann, Why Opera Education? a RESEO research report (RESEO, 2003).

LIPOVETSKY, Guilles; Serroy, Jean, La pantalla global. Cultura mediática y cine en la era hipermoderna (Barcelona, Anagrama, 2009).

Morris, Christopher, «Digital Diva: Opera on video» (Opera Quarterly, Vol. 26, 2010), pp. 96-119. 
Radigales, Jaume, L'Òpera. Música, teatre i espectacle, (Barcelona, Enciclopedia Catalana, 1993).

-, «La ópera y el cine: afinidades electivas», en La música en los medios audiovisuales, (Salamanca, Universitaria, 2007), pp. 59-84.

-, «Playback Problems when Filming Opera for the Screen: Two Case Studies» en Opera and Video. Technology and Spectatorship (Bern, Peter Lang, 2012), pp. 115-127.

—, Villanueva, Isabel, «Le rôle de l'opéra dans le cinéma primitif: Étude des cas» (Performing New Media, 1895-1915. Twelfth International Domitor Conference, Brighton, $\mathrm{UK}, 2012)$.

RoseluI, John, «La ópera como acontecimiento social», en Historia ilustrada de la ópera (Barcelona, Paidós Ibérica, 1998), pp.450-482.

SÁnchEz, Sergi, «La ópera en pantalla grande. Entrevista a José Batlle», (Opera Actual, vol. 116, 2008), pp. 36-37.

Schroeder, David, Cinema's Illusions, Opera's Allure. (New York, The Continuum International Publishing Froup, 2002).

SHEIL, Àine, «The Opera Director's Voice: DVD 'Extras' and the Question of Authority», en Opera and Video. Technology and Spertatorship. (Berna, Peter Lang, 2012), pp. 129-150.

Silverstone, Roger, Television and Everyday Life, (New York, Routledge, 1994).

Sмiтн, Janice, «Opera as an Interdisciplinary Art», (Music Educators Journal, Vol. 79, 1992), pp. 21-61.

TAmbling, Jeremy, Opera, Ideology and Film (New York, St. Martin's Press, 1987).

Tomlinson, Gary, Canto metafísico: un ensayo sobre la ópera. (Barcelona, Idea Books, 2001).

Villanueva-Bentto, Isabel, Mediatización audiovisual de la ópera como proceso de apertura a nuevos públicos; el caso de la obra Don Giovanni de W. A. Mozart. (tesis doctoral, Barcelona, Universitat Internacional de Catalunya, 2014), pp. 621.

Recibido : 15 de octubre de 2017

Aceptado para revisión por pares: 21 de noviembre de 2017

Aceptado para publicación: 31 de mayo de 2018 